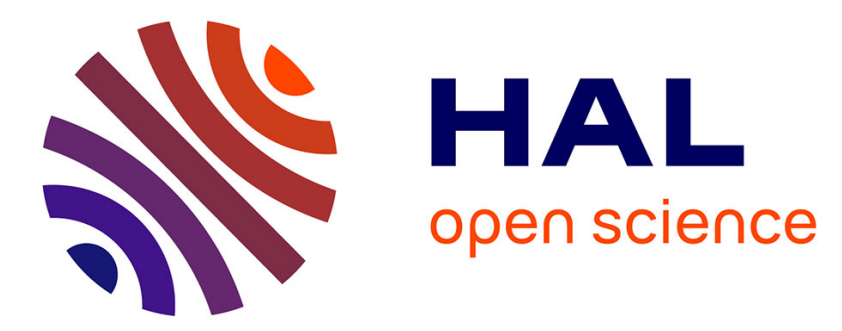

\title{
Marine Microbial Diversity as a Source of Bioactive Natural Products
}

\author{
Didier Stien
}

\section{To cite this version:}

Didier Stien. Marine Microbial Diversity as a Source of Bioactive Natural Products. Marine drugs, 2020, 18 (4), pp.215. 10.3390/md18040215 . hal-02861020

\section{HAL Id: hal-02861020 \\ https://hal.science/hal-02861020}

Submitted on 5 Nov 2020

HAL is a multi-disciplinary open access archive for the deposit and dissemination of scientific research documents, whether they are published or not. The documents may come from teaching and research institutions in France or abroad, or from public or private research centers.
L'archive ouverte pluridisciplinaire HAL, est destinée au dépôt et à la diffusion de documents scientifiques de niveau recherche, publiés ou non, émanant des établissements d'enseignement et de recherche français ou étrangers, des laboratoires publics ou privés. 


\title{
Marine Microbial Diversity as a Source of Bioactive Natural Products
}

\author{
Didier Stien (1D)
}

Laboratoire de Biodiversité et Biotechnologie Microbiennes, Sorbonne Université, CNRS, LBBM, Observatoire Océanologique, 66650 Banyuls-sur-Mer, France; didier.stien@cnrs.fr

Some 3.5 billion years ago, microorganisms were the first to colonize Earth. They have gradually evolved, within intricate systems of microbial and macroscopic species, to occupy virtually all the available niches on the planet. Genetic drift and natural selection have molded the phenotypic expression of a trillion different microbial species [1], shaping their metabolisms and offering ever-more advantageous abilities to expand, with the production of new metabolites being one key to the fitness and evolutionary success of new species [2].

The rate of discovery of new natural products of microbial origin has increased significantly since the 1970s with the advent of modern methods of purification and structural determination, and later, with holistic approaches to chemical analysis and genetic information-based exploration of natural chemodiversity [3-6]. With these tools in hand and the exploration of innovative and ecologically relevant sources of microorganisms, it is possible to rapidly expand the exploration of chemodiversity on a global scale, and eventually isolate innovative compounds. It should be noted that the enthusiasm to discover new scaffolds is not necessarily relevant in the context of the search for active or useful natural products. Structural modifications that do not affect the core scaffold of a metabolite may provide a significant benefit that can be developed for a therapeutic use. A notable example is in the immense diversity of terpenes built on a limited number of scaffolds. Terpenes have different functional roles-and therefore different biological activities—and have largely contributed to the diversification of higher plants [2,7].

Today, marine microbes can still be regarded as a relatively underappreciated potential source of active compounds yet to be discovered. Some microorganisms can live freely in the water column, while many others live in association. For example, sponges host microorganisms that contribute to their holometabolome, while many coral species host microalgae and symbiotic prokaryotes. Furthermore, many microorganisms contribute to the construction of interspecific biofilms covering biotic and abiotic surfaces. While recent advances in natural-product science now provide access to an unknown dimension of chemodiversity, metabolic engineering will eventually allow the production of active marine compounds in amounts necessary for pharmaceutical development.

The Special Issue "Marine Microbial Diversity as a Source of Bioactive Natural Products" was aimed at collecting papers with up-to-date information regarding the characterization of marine microbes' metabolic diversity and the evaluation of the therapeutic potential of marine microbes' metabolites. The interest of the Special Issue was also to show that the exploration of underrated reservoirs of marine microorganisms can lead to the discovery of valuable secondary metabolites. In total, 10 articles were accepted and included in the Special Issue.

Most of the articles in this special issue deal with marine fungi, biological and chemical diversity, and their active metabolites. This may be a sign that marine fungi have been under studied to date, and are perceived by many researchers as an important source of discovery in this field [8]. Focusing on marine Arthrinium spp. isolates, Heo et al. conducted a phylogenetic analysis based on internal transcribed spacers, nuclear large subunit rDNA, $\beta$-tubulin, and translation elongation factor region 
sequences [9]. The 28 analyzed strains were obtained by cultivation of seaweed tissues (including several Sargassum fulvellum individuals) and Arctoscopus japonicus egg masses. It was found that the 28 isolates were in fact 15 species, 11 of which being new to Science. Most of the fungal extracts exhibited radical-scavenging activity, and some showed antifungal activity, tyrosinase inhibition, and quorum sensing inhibition. Interestingly, three species were found in both S. fulvellum and A. japonicus egg masses, perhaps because these fish usually lay eggs on S. fulvellum. The known compound gentisyl alcohol was found to be responsible for the radical-scavenging activity of two of the Arthrinium extracts. A fungal diversity analysis was also conducted on decommissioned salterns and neighboring mudflats in the Yellow Sea of South Korea [10]. Comparative fungal community analysis showed that the salterns that had been abandoned for more than 35 years had recovered to mudflats. The Yongyudo saltern was abandoned less than one year before the analysis and had not recovered. Its fungal community was more diverse and was dominated by Entorrhizomycota, while Chytridiomycota and Mortierellomycota dominated elsewhere. It has been hypothesized that Entorrhizomycota may include plant pathogenic fungi and that the dominance of this phylum may originate from the occurrence of their host plants at the initial stage of ecological succession after the saltern was abandoned. It should be mentioned that a large number of fungi could not be identified, indicating a lack of DNA-based phylogenetic information on marine fungi. Eventually, 53 fungal strains were isolated from the different sampling locations. The cultivable fungi were not necessarily the main taxa from the community analyses. A total of 18 isolates were possibly new species, and the authors provide the antioxidant, antifungal, tyrosinase inhibition, and quorum quenching activity of all isolates.

Fungal spores are easily dispersed and are detectable in community analyses. As a result, not all fungi detected in marine environments by rDNA-based analysis are genuine marine species. The challenging question of the isolation of marine fungi sensu stricto is key to the future exploration of the chemical diversity of marine fungi, and possibly the exploitation of their secondary metabolites. A best-practice guide for the isolation of marine fungi from different matrixes and their conservation is presented by Overy et al. [11]. Generalist, osmotolerant/halotolerant genera such as Aspergillus and Penicillium are highly cited in the literature but taxonomic groups composed predominantly of marine fungi sensu stricto such as Halosphaeriaceae, Torpedosporales, and Lulworthiales have been little studied for now. It should also be noted that mycologists have been studying marine fungi for decades, and that currently cryopreserved marine fungi may represent an easily accessible source for the exploration of their chemical diversity and the isolation of active secondary metabolites.

One of the sources frequently explored in the search for marine fungi are sedimentary deposits. Examination of the full genome of the marine-derived fungus Penicillium brasilianum HBU-136, isolated from the Bohai sea in China, highlighted that the strain harbors multiple non-ribosomal peptide synthetase (NRPS) biosynthetic gene clusters (BGC), including one showing high similarity to the BGC of fumitremorgins A-C in the fungus Aspergillus fumigatus [12]. The strain was already known to produce a spirocyclic diketopiperazine alkaloid and cyclotryprostatin $B$ when cultivated on rice medium. More fermentation conditions were experimented and it was eventually discovered that three new and unusual indole-diketopiperazines 1-3 were produced by fermentation in a rice medium supplemented with $1 \% \mathrm{MgCl}_{2}$ (Figure 1). The proposed BGC is likely responsible for the synthesis of these metabolites. Compound 1 was cytotoxic on HL-60 cells $(6.0 \mu \mathrm{M})$, and compounds 2 and 3 were active on MCF-7 cell line (7.6 and $10.8 \mu \mathrm{M}$, respectively). The marine-derived fungus Aspergillus fumigatus CUGBMF170049 was also isolated from the Bohai sea sediments and was shown to produce new pseurotin analogs 4 and $\mathbf{5}$ (Figure 1) [13]. These metabolites were identified by thorough analysis of spectroscopic data, but unfortunately, were not active in the antimicrobial assays used in this work. Incidentally, the known compound helvolic acid isolated from the same fungus was very active on both Staphylococcus aureus and methicillin-resistant $S$. aureus, with a minimal inhibitory concentration (MIC) of $0.78 \mu \mathrm{g} / \mathrm{mL}$. The fungus Geosmithia pallida FS140 was isolated from a sediment collected at $2403 \mathrm{~m}$ depth in the South China Sea [14]. Twelve diketopiperazines, including the three new thiodiketopiperazines geospallins A-C (6-8), were isolated from this fungus (Figure 1). The three 
new compounds exhibited substantial angiotensin-converting enzyme inhibitory activity, with $\mathrm{IC}_{50}$ values of $29-35 \mu \mathrm{M}$.<smiles>COc1ccc2c(c1)NC1(NC1=O)C(=O)[C@@]1(O)C(=O)N3CCC[C@]3(O)C(=O)N1C2=O</smiles>

1<smiles>[X]C12CCCN1C(=O)[C@]1(O)C(=O)N2C(OC)c2[nH]c3cc(OC)ccc3c21</smiles>

2: $\mathrm{X}=\mathrm{OH}$ 3: $\mathrm{X}=\mathrm{H}$

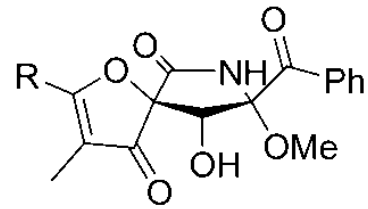

4: $R=1$-hydroxyhexyl

5: $R=5$-ethylfuran-2-yl

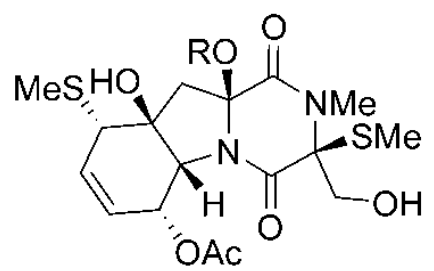

6: $\mathrm{R}=\mathrm{Me}$

7: $\mathrm{R}=\mathrm{H}$

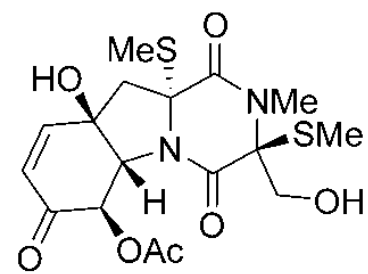

8

Figure 1. Compounds isolated from marine-sediment-derived fungi.

In the sea, many fungal species are associated with macroscopic organisms $[9,11,15]$. The isolation of marine fungi from macroorganisms' tissues may in fact be a fairly straightforward way of isolating marine fungi sensu stricto. The fungus Aspergillus flocculosus 168ST-16.1 was isolated from the algae Padina sp., collected at a depth of $10 \mathrm{~m}$ in Da Nang, Vietnam [16]. Five new sesterterpene ophiobolins together with four known ones were isolated from a broth culture of this fungus and identified by spectroscopic methods. Interestingly, all these compounds were active against six cancer cell lines with $50 \%$ growth inhibition $\left(\mathrm{GI}_{50}\right)$ values in the range of 0.14 to $2.01 \mu \mathrm{M}$. The new compound 14,15-dehydro-6-epi-ophiobolin K (9, Figure 2) was among the most active ones, with a GI $_{50}$ of about $0.2 \mu \mathrm{M}$ on all tested cell lines. The fungal strain Botryosphaeria ramosa L29 was isolated as an endophyte of the mangrove plant species. Four new isocoumarin derivatives, namely botryospyrones A, B (10), C, and D (Figure 2) were isolated from this fungus. Interestingly, a fifth compound (11) was produced only when the culture medium was supplemented with the host plant flavonoid (2R,3R)-3,5,7-trihydroxyflavanone 3-acetate, which had been found to slightly inhibit the endophyte growth. Owing to the ease of isomerization of animals by successive ring-opening and ring-closing steps, it is expected that such compound would eventually generate the more stable stereoisomer, i.e., the cis ring junction isomer. Further, the ${ }^{13} \mathrm{C}$ NMR spectrum of compound $\mathbf{1 1}$ is similar enough to the one previously reported in the literature to conclude that the proposed structure was probably erroneous [17]. Compound 11 is in fact likely the ( $3 \mathrm{a} R, 8 \mathrm{a} S)$-1-acetyl-1,2,3,3a,8,8a-hexahydropyrrolo[2,3-b]indol-3a-ol rather than the $(3 a S, 8 a S)$ stereoisomer. Three coumarins and compound $\mathbf{1 1}$ were evaluated in vitro for antifungal activity toward three phytopathogenic fungi. It is interesting to point out that compound 11, which is only produced by the fungus exposed to a metabolite of the plant, was the most active, with MIC values in the $28-57 \mu \mathrm{M}$ range. 

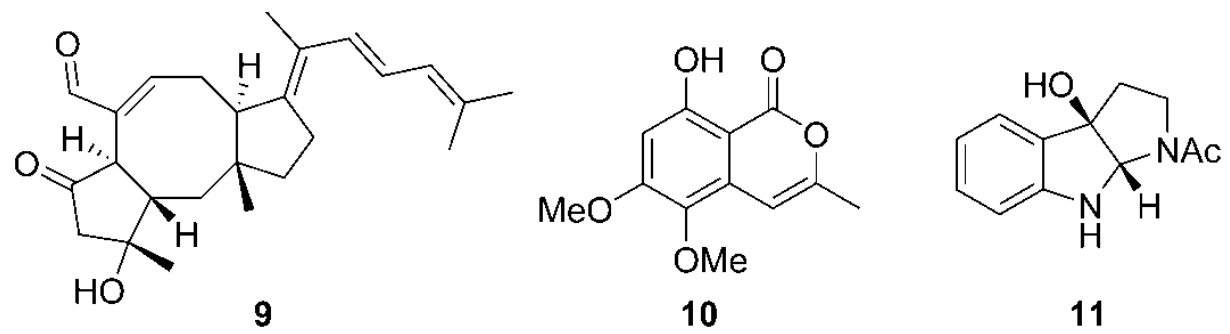

(alternative structure proposal)

Figure 2. Examples of secondary metabolites isolated from fungi associated to algae and plants.

Finally, describing and understanding the metabolic diversity of marine species will allow a better understanding of the whole marine ecosystem, a better understanding of the mechanisms that regulate interspecific interactions in the sea, and possibly, a better understanding of the evolutionary processes involved. Moreover, the sea is the cauldron of a great diversity of useful and valuable compounds, whether known or not. As such, many marine microorganisms can become important sources of compounds useful to humankind. The carotenoid-producing yeast strain Rhodotorula sp. RY1801 was isolated from the exposed intertidal zone along the South Yellow Sea in Dongtai, China [18]. The culture conditions were optimized to increase the microbial biomass and the carotenoid yield of the strain. Eventually, it was possible to reach nearly $1 \mathrm{mg} / \mathrm{L}$ carotenoids in the culture, demonstrating that this fast growing Rhodotorula sp. strain may be used for the commercial production of carotenoids. The comparison of the phylogenetic and metabolomic profiles of 12 microalgal species from different lineages provided novel insights into the potential of chemotaxonomy in marine phytoplankton [19]. The most abundant and diversified metabolites identified over the 12 strains were polar lipids and pigments. Historically, analysis of pigment composition has been used to assist the classification of microalgae. Here, it was found that lipid classes and some specific lipids within classes may serve as phylogenetic markers. For example, within the tested Mamiellales, the Ostreococcus genus differs by the presence of two monogalactosyldiacylglycerols (MGDG 20:5/16:3 and 16:1/16:1), and the species $O$. tauri has six 1,2-diacylglyceryl-3-O-4'-(N,N,N-trimethyl)-homoserines (DGTSs) that are not found in O. mediterraneus. Overall, a good overlap of phylogenetic and chemotaxonomic signals was demonstrated, in particular when the analysis focused on the major metabolites of algae, and evolutionary divergence between species could be inferred in good congruence with the phylogenies. These results support the hypothesis of a metabolomics equivalent to the "molecular clock" based on the analysis of sequence data.

As seen from the above synopsis, the papers included in this Special Issue provide an interesting overview of chemical diversity of marine fungi and algae. New, bioactive, marine-derived fungal metabolites were isolated and characterized. The articles presented in this Special Issue underline the central role of the sea as a provider of valuable chemicals for human use.

In conclusion, the Guest Editor thanks all the authors who contributed to this Special Issue, all the reviewers for evaluating the submitted manuscripts, and the Editorial board of Marine Drugs, especially, Orazio Taglialatela-Scafati, Editor-in-Chief of the journal, and Estelle Fan, Assistant Editor, for their kind help in bringing this book into reality.

Conflicts of Interest: The author declares no conflict of interest.

\section{References}

1. Locey, K.J.; Lennon, J.T. Scaling laws predict global microbial diversity. Proc. Natl. Acad. Sci. USA 2016, 113, 5970-5975. [CrossRef] [PubMed]

2. Courtois, E.A.; Dexter, K.G.; Paine, C.E.T.; Stien, D.; Engel, J.; Baraloto, C.; Chave, J. Evolutionary patterns of volatile terpene emissions across 202 tropical tree species. Ecol. Evol. 2016, 6, 2854-2864. [CrossRef] [PubMed] 
3. Pye, C.R.; Bertin, M.J.; Lokey, R.S.; Gerwick, W.H.; Linington, R.G. Retrospective analysis of natural products provides insights for future discovery trends. Proc. Natl. Acad. Sci. USA 2017, 114, 5601-5606. [CrossRef] [PubMed]

4. Wolfender, J.-L.; Litaudon, M.; Touboul, D.; Ferreira Queiroz, E. Innovative omics-based approaches for prioritisation and targeted isolation of natural products - new strategies for drug discovery. Nat. Prod. Rep. 2019, 36, 855-868. [CrossRef] [PubMed]

5. Gerwick, W.H.; Moore, B.S. Lessons from the past and charting the future of marine natural products drug discovery and chemical biology. Chem. Biol. 2012, 19, 85-98. [CrossRef] [PubMed]

6. Lauritano, C.; Ferrante, M.I.; Rogato, A. Marine natural products from microalgae: An -omics overview. Mar. Drugs 2019, 17, 269. [CrossRef] [PubMed]

7. Rodrigues, A.M.S.; Eparvier, V.; Odonne, G.; Amusant, N.; Stien, D.; Houël, E. The antifungal potential of (Z)-ligustilide and the protective effect of eugenol demonstrated by a chemometric approach. Sci. Rep. 2019, 9, 8729. [CrossRef] [PubMed]

8. Gladfelter, A.S.; James, T.Y.; Amend, A.S. Marine fungi. Curr. Biol. 2019, 29, R191-R195. [CrossRef] [PubMed]

9. Heo, Y.M.; Kim, K.; Ryu, S.M.; Kwon, S.L.; Park, M.Y.; Kang, J.E.; Hong, J.-H.; Lim, Y.W.; Kim, C.; Kim, B.S.; et al. Diversity and ecology of marine algicolous Arthrinium species as a source of bioactive natural products. Mar. Drugs 2018, 16, 508. [CrossRef]

10. Heo, Y.M.; Lee, H.; Kim, K.; Kwon, S.L.; Park, M.Y.; Kang, J.E.; Kim, G.-H.; Kim, B.S.; Kim, J.-J. Fungal diversity in intertidal mudflats and abandoned solar salterns as a source for biological resources. Mar. Drugs 2019, 17, 601. [CrossRef]

11. Overy, D.P.; Rämä, T.; Oosterhuis, R.; Walker, A.K.; Pang, K.-L. The neglected marine fungi, sensu stricto, and their isolation for natural products' discovery. Mar. Drugs 2019, 17, 42. [CrossRef] [PubMed]

12. Zhang, Y.-H.; Geng, C.; Zhang, X.-W.; Zhu, H.-J.; Shao, C.-L.; Cao, F.; Wang, C.-Y. Discovery of bioactive indole-diketopiperazines from the marine-derived fungus Penicillium brasilianum aided by genomic information. Mar. Drugs 2019, 17, 514. [CrossRef] [PubMed]

13. Xu, X.; Han, J.; Wang, Y.; Lin, R.; Yang, H.; Li, J.; Wei, S.; Polyak, S.W.; Song, F. Two new spiro-heterocyclic $\gamma$-lactams from a marine-derived Aspergillus fumigatus strain CUGBMF170049. Mar. Drugs 2019, 17, 289. [CrossRef] [PubMed]

14. Sun, Z.-H.; Gu, J.; Ye, W.; Wen, L.-X.; Lin, Q.-B.; Li, S.-N.; Chen, Y.-C.; Li, H.-H.; Zhang, W.-M. Geospallins A-C: new thiodiketopiperazines with inhibitory activity against angiotensin-converting enzyme from a deep-sea-derived fungus Geosmithia pallida FS140. Mar. Drugs 2018, 16, 464. [CrossRef] [PubMed]

15. Rédou, V.; Vallet, M.; Meslet-Cladière, L.; Kumar, A.; Pang, K.-L.; Pouchus, Y.-F.; Barbier, G.; Grovel, O.; Bertrand, S.; Prado, S.; et al. Marine fungi. In The marine microbiome; Stal, L.J., Cretoiu, M.S., Eds.; Springer International Publishing: Cham, Switzerland, 2016; pp. 99-153. ISBN 978-3-319-33000-6.

16. Choi, B.-K.; Trinh, P.T.H.; Lee, H.-S.; Choi, B.-W.; Kang, J.S.; Ngoc, N.T.D.; Van, T.T.T.; Shin, H.J. New ophiobolin derivatives from the marine fungus Aspergillus flocculosus and their cytotoxicities against cancer cells. Mar. Drugs 2019, 17, 346. [CrossRef] [PubMed]

17. Yang, S.-W.; Cordell, G.A. Metabolism studies of indole derivatives using a staurosporine producer, Streptomyces staurosporeus. J. Nat. Prod. 1997, 60, 44-48. [CrossRef] [PubMed]

18. Zhao, Y.; Guo, L.; Xia, Y.; Zhuang, X.; Chu, W. Isolation, identification of carotenoid-producing Rhodotorula sp. from marine environment and optimization for carotenoid production. Mar. Drugs 2019, 17, 161. [CrossRef] [PubMed]

19. Marcellin-Gros, R.; Piganeau, G.; Stien, D. Metabolomic insights into marine phytoplankton diversity. Mar. Drugs 2020, 18, 78. [CrossRef] [PubMed]

(C) 2020 by the author. Licensee MDPI, Basel, Switzerland. This article is an open access article distributed under the terms and conditions of the Creative Commons Attribution (CC BY) license (http://creativecommons.org/licenses/by/4.0/). 